\title{
Afectaciones por posible asociación de eventos hidrometeorológicos y geológicos en los municipios de Calcahualco y Coscomatepec, Veracruz
}

Recibido: 03/02/2016 · Aceptado: 22/03/2016

Marco Aurelio Morales Martínez* / Carlos Manuel Welsh Rodríguez Centro de Ciencias de la Tierra, Universidad Veracruzana

Laura C. Ruelas Monjardín El Colegio de Veracruz

Blake Weissling Department of Geological Sciences, College of Sciences University of Texas at San Antonio

Katrin Sieron / Carolina Andrea Ochoa Martínez Centro de Ciencias de la Tierra, Universidad Veracruzana

\section{Resumen}

Luego de la entrada del huracán Ernesto a Veracruz en 2012, en los municipios de Calcahualco y Coscomatepec se produjo remoción en masa debido a flujos de agua mezclados con sedimentos, en la parte alta de la cuenca de los ríos Jamapa y Tliapa, que nacen en el Parque Nacional Pico de Orizaba. En este trabajo se parte de la hipótesis de que las lluvias ocasionadas por el huracán no fueron la única causa; asimismo, se hace una aproximación a los impactos en la población, en la infraestructura carretera, así como en la superficie del suelo, debido a que su probable incidencia representa un riesgo para las poblaciones que habitan en las partes bajas de la cuenca. Este trabajo incluye un análisis descriptivo de la hemerográfica de organizaciones gubernamentales y civiles que registraron los impactos del huracán en la zona de estudio, así como el resultado del reconocimiento en campo de las áreas donde hubo remoción en masa.

Palabras clave: Desastre, vulnerabilidad, Pico de Orizaba, procesos de remoción en masa.

*Correo electrónico: marcmorales@uv.mx 


\title{
Damage by possible association between hidro meteorological and geological events in the municipalities of Calcahualco y Coscomatepec, Veracruz
}

\author{
Marco Aurelio Morales Martínez* / Carlos Manuel Welsh Rodríguez \\ Centro de Ciencias de la Tierra, Universidad Veracruzana \\ Laura C. Ruelas Monjardín \\ El Colegio de Veracruz \\ Blake Weissling \\ Department of Geological Sciences, College of Sciences \\ University of Texas at San Antonio \\ Katrin Sieron / Carolina Andrea Ochoa Martínez \\ Centro de Ciencias de la Tierra, Universidad Veracruzana
}

\begin{abstract}
In 2012 Hurricane Ernesto left extensive damage in all sectors of the Veracruz state, but in the case of the municipalities of Calcahualco and Coscomatepec (Veracruz, Mexico) there is evidence of mass movement caused by flowing water mixed with sediments in the upper basin of Tliapa and Jamapa rivers, initiating within the Pico de Orizaba National Park. The analysis allows constructing the hypothesis that the rainfall caused by Hurricane Ernesto in 2012 was not the only cause of the damages. This paper seeks to establish a first approach to the investigation of this event, specifically related to the impacts on the population, road infrastructure and the earth's surface, and because it's likely re-occurrence in the future represents a risk to people living in the lower parts of the basin. This study includes a descriptive analysis of newspapers and governmental and civilian information sources, as well as a recognition of the areas that provide evidences of the mass movement events that took place in the upper part of the Jamapa and Tliapa river basins.
\end{abstract}

KEY WORDS:

*E-mail: marcmorales@uv.mx 


\section{Introducción}

El cambio climático antropógeno y los procesos socioeconómicos en los que se incluye la adaptación y mitigación son detonadores de los peligros relacionados con el clima, la vulnerabilidad y la exposición de los sistemas humanos, y a su vez construyen el riesgo de los impactos ligados al clima (IPCC, 2012).

El Panel Intergubernamental de Cambio Climático (Intergovernmental Panel on Climate Change, IPCC, 2012) plantea que los desastres son cambiantes en el tiempo y el espacio, dependiendo de los factores económicos, sociales, geográficos, demográficos, culturales, institucionales, de gobernanza y ambientales. La observación de estos factores ha permitido concluir que los actuales patrones de distribución de la población han influido en el incremento de la exposición y vulnerabilidad de la sociedad a los eventos hidrometereológicos extremos (IPCC, 2013).

De acuerdo con cifras publicadas por el Centro Nacional de Prevención de Desastres (Cenapred), de 2002 a 2012 Veracruz fue el estado de la república con mayor número de daños por fenómenos hidrometeorológicos extremos. Durante ese periodo, se tienen registros de 182 eventos, que ocasionaron 109 decesos y daños materiales por aproximadamente 54000 millones de pesos (García, Marín, Méndez y Reyes, 2014). También destaca el año 2012 como el segundo con mayor cantidad de decesos (22) a causa de los eventos hidrometeorológicos extremos, solo debajo de 2010, con 25 muertes registradas (García et al., 2014). Las tendencias de incremento en la ocurrencia de los eventos extremos en el estado de Veracruz (Ochoa Martínez, Welsh, Bonilla y Morales, 2013) indican que la gestión del riesgo es un reto constante para la sociedad y las autoridades (IPCC, 2012).

En el presente estudio se analizaron las afectaciones relacionadas con los eventos hidrometereológicos extremos recientes en la zona noreste del Parque Nacional Pico de Orizaba (PNPo), que incluye parte de las barrancas de los ríos Jamapa y Tecoac/Tliapa; la primera en el municipio de Calcahualco y la segunda en el de Coscomatepec, ambas en Veracruz. El PNPO se localiza al extremo este de la Faja Volcánica en México entre las coordenadas geográficas $18^{\circ} 56^{\prime} 30^{\prime \prime}$ y $19^{\circ} 09^{\prime} 30^{\prime \prime}$ de latitud norte y $97^{\circ} 12^{\prime} 30^{\prime \prime}$ y $97^{\circ} 22^{\prime} 30^{\prime \prime}$ de longitud oeste (Vargas, 1984). En el PNPo existen tres tipos de clima: de hielo permanente (EF), frío con lluvias en verano (ЕтH) y semifrío-subhúmedo con isotermas de 
-2 a $12{ }^{\circ} \mathrm{C}$ e isoyetas de 1000 a $1200 \mathrm{~mm}$. Además, se encuentran los ríos Jamapa, Vaquería, Piedra Pintada, El Candelero y Cardosanto; los arroyos Puente de Viga, Paso de Buey y San Antonio Blanco, y el manantial Cardosanto (Vargas, 1997).

\section{Antecedentes}

Las lluvias intensas que ocurrieron el 9 de agosto de 2012 incrementaron la erosión superficial y ocasionaron la remoción de material rocoso y arenoso a altitudes superiores a los $4200 \mathrm{msnm}$, produciendo flujos de agua con sedimentos que drenaron hacia las cuencas de los ríos Jamapa y Tliapa laderas abajo, en el área dentro y fuera del PNPO. Un suceso similar ya se había documentado del 2 al 5 de junio de 2003 (Rodríguez, Mora-González y Murrieta-Hernández, 2006) en el flanco sur-sureste del volcán Pico de Orizaba, trayendo como consecuencia el desbordamiento de los ríos Chiquito y Carbonera; este evento originó severos daños en la localidad de Balastrera, municipio de Nogales, donde se rompió un poliducto de gas que generó una explosión, causando daños materiales y pérdida de vidas humanas.

En ambos casos, los flujos iniciaron en áreas altas del volcán, donde la mayor parte del año no hay escorrentía superficial significativa. Este tipo de fenómeno forma parte de los procesos de remoción en masa (definidos y clasificados por Sharpe, 1938 y Varnes, 1958, p. 27 y 1978, p. 22), dentro de la categoría de los flujos de agua y sedimento que en diferentes porcentajes se mueven ladera abajo por causa de la gravedad. Estos flujos se clasifican de una manera simplificada, dependiendo de la relación agua-sedimento, en flujos de corriente normal, flujos hiperconcentrados (con un contenido de sedimento entre $40 \mathrm{y}$ $80 \%$ en peso o de 20 a $60 \%$ en porcentaje de volumen) y flujos de detrito (por ejemplo Smith, 1986; Pierson y Costa, 1987, p. 11).

Durante la temporada de lluvias de 2012, del $1^{\circ}$ al 10 de agosto, se presentó en el océano Atlántico el huracán Ernesto (figura 1) de categoría 2 (Brown, 2013). El fenómeno tocó en dos ocasiones territorio mexicano. Su primer impacto fue el 7 de agosto a las 22:00 horas, en las inmediaciones del Majahual, Quintana Roo, como huracán con categoría 1. Luego continuó su trayectoria por toda la Península de Yucatán, hasta nuevamente salir al mar, el 8 de agosto a las 22:00 horas ya como tormenta tropical al sureste de Punta Xochen, Campeche, 
volviendo a tocar tierra al occidente de Coatzacoalcos, Veracruz, el 9 de agosto a las 13:00 horas. A partir de ese momento se mantuvo en tierra, atravesando los municipios veracruzanos de Acayucan, Cosamaloapan y Tierra Blanca, degradándose a depresión tropical a primera hora del 10 de agosto, ya en territorio del estado de Puebla. El último registro se dio a las 10:00 horas del mismo día en Huajuapan de León, Oaxaca (Conagua, 2012).

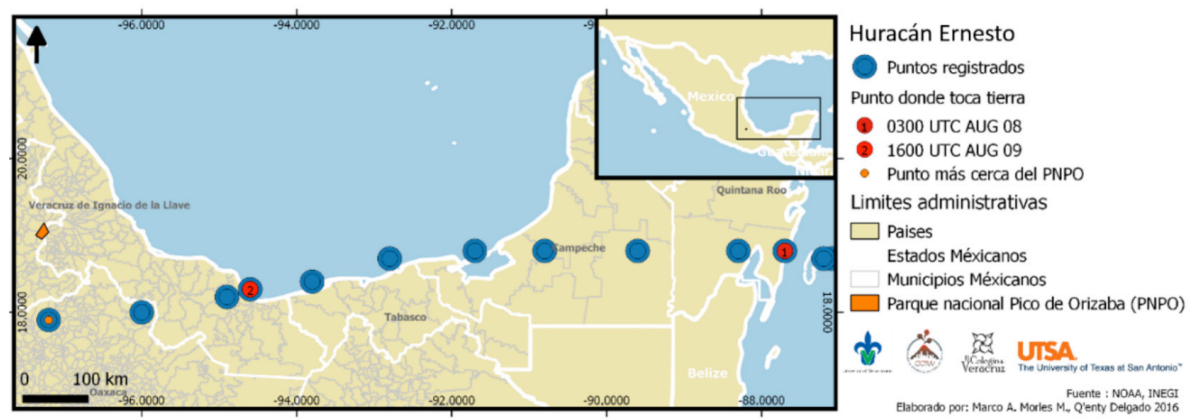

Figura 1. Trayectoria del huracán Ernesto del 7 al 10 de agosto de 2012

Ernesto trajo lluvias a gran parte del centro y sur de México, resultando afectado el estado de Veracruz de manera directa el 9 y 10 de agosto. La declaratoria de emergencia publicada por la Secretaría de Gobernación en el Diario Oficial de la Federación el 23 de agosto de 2012 incluye a localidades de los municipios de Calcahualco y Coscomatepec (Secretaría de Gobernación, 2012).

Como resultado del paso del fenómeno, a finales de agosto de 2012, caminantes de alta montaña del Pico de Orizaba reportaron (Joaquín Canchola Limón, prestador de servicios turísticos en el PNPO, Talchichuca, Puebla, 2012, comunicación personal) que en la barranca del Jamapa dentro del pNPo se presentaron considerables socavamientos, los cuales comenzaban desde arriba del albergue alpino Piedra Grande; lo anterior se relacionó con las fuertes lluvias en el área.

Dos estaciones climatológicas del Servicio Meteorológico Nacional (Comisión Nacional del Agua), 21073 y 21158, registraron 91.6 y 100 mm de precipitación, respectivamente, para el 9 de agosto. Estas estaciones se localizan entre 10 y $12 \mathrm{~km}$ al sur y suroeste de la cabeza de la cuenca hidrográfica Jamapa. 

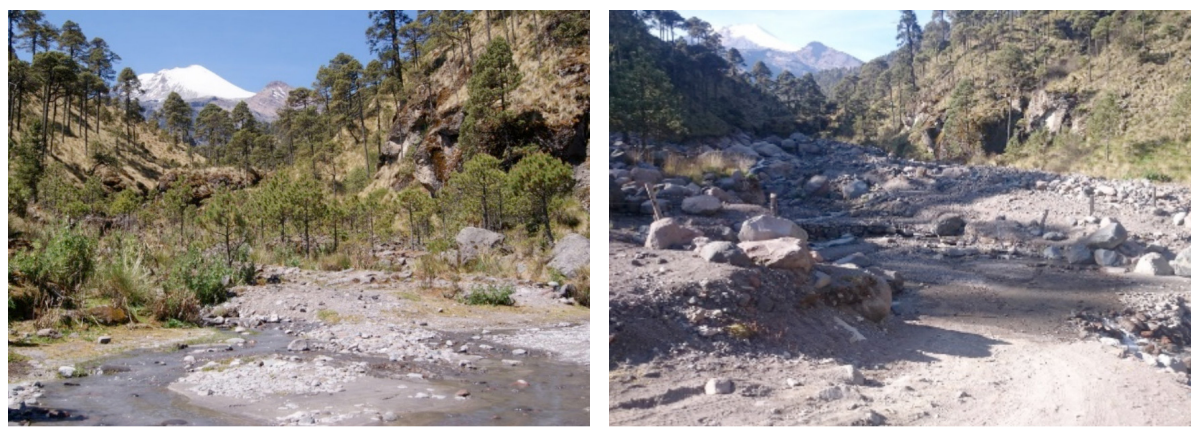

FiguRa 2. Evidencia de la modificación del cauce de río y los depósitos asociados al evento. Fotografía a la izquierda, mayo de 2011 (Galán, 2011), anterior al evento, y fotografía a la derecha, junio de 2014 (Morales, 2015), posterior al evento, a 3350 msnm, PNPO.

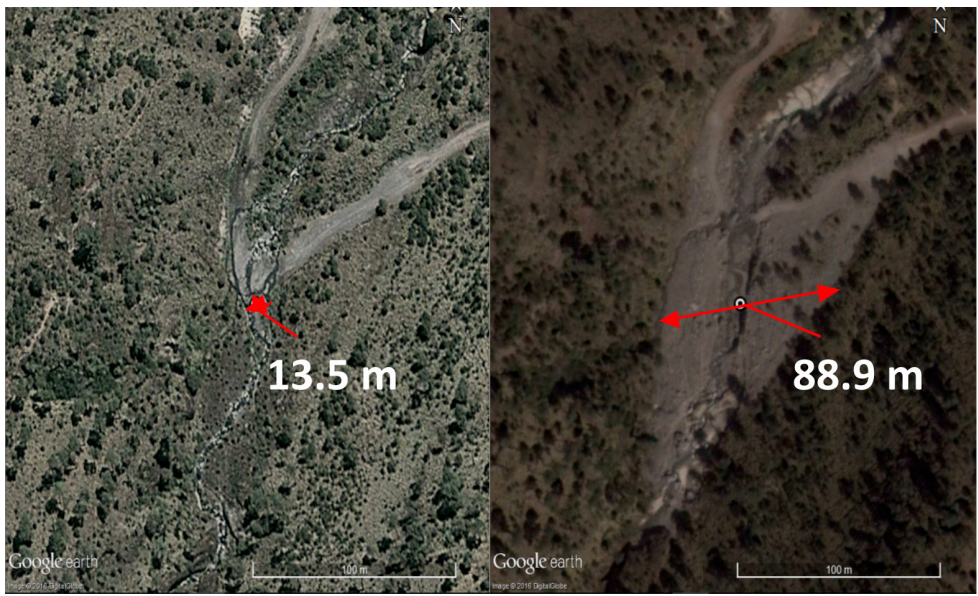

FiguRA 3. Evidencia de erosión causada por flujos a 3350 msnm, PNPO. Punto central de ambas imágenes: $19.081676^{\circ} \mathrm{N} 97.253860^{\circ} 0$. Imagen a la izquierda, 21 de mayo de 2011 , imagen a la derecha, $1^{\circ}$ de marzo de 2014 (Google Earth®, 2015).

El promedio de la precipitación acumulada durante el evento, basado en el registro de 48 estaciones dentro de un radio de $75 \mathrm{~km}$ del PNPO, fue de $99.5 \mathrm{~mm}$ con una desviación estándar de $63.3 \mathrm{~mm}$. Los totales de precipitación de las estaciones localizadas en altitudes por debajo de $2500 \mathrm{msnm}$ no han sido significativamente distintos a los de las ubicadas por encima de $2500 \mathrm{msnm}$, con un promedio de 97.9 y $106.2 \mathrm{~mm}$, respectivamente. Sin embargo, se notó una fuerte 
diferencia en la precipitación registrada en estaciones al oeste del Pico de Orizaba (estado de Puebla) comparada con las del este (estado de Veracruz). El promedio de los registros de precipitación de las estaciones del este fue de $155.5 \mathrm{~mm}$ (con una desviación estándar de $52.8 \mathrm{~mm}$ ), comparado con $61.4 \mathrm{~mm}$ (con una desviación estándar de $52.8 \mathrm{~mm}$ ) de lo registrado en el oeste. La distribución de la precipitación en ambos lados del Pico de Orizaba para este huracán es altamente representativa de los patrones regionales de precipitación anual y estacional. La única otra estimación de la precipitación para este evento, disponible para el presente estudio, son los datos del satélite trmm (Tropical Rainfall Measurement Mission) (NASA, 2016). Respecto a la duración del huracán Ernesto, el valor estimado del TRMм fue de $221 \mathrm{~mm}$ para una región definida por un pixel de 25 x $25 \mathrm{~km}$ (abarcando todo el PNPO), valor que representa aproximadamente la quinta parte del total anual, el cual se encuentra entre los 900 y $1600 \mathrm{~mm}$ de precipitación acumulada en el área de estudio (INEGI, 2009a y 2009b).

La comunicación de Joaquín Canchola asentó un antecedente para la verificación en campo. Se encontró que en el punto donde el naciente río Jamapa atraviesa el camino rumbo al albergue alpino Piedra Grande, situado en las coordenadas lat. $19.082986^{\circ} \mathrm{N}$ long. $-97.253366^{\circ} \mathrm{O}$ y que forma parte de la cuenca alta homónima, a una elevación de $3553 \mathrm{msnm}$, se presentó un socavamiento mayor a los $80 \mathrm{~m}$ de ancho y $5 \mathrm{~m}$ de profundidad (figuras 2 y 3 ).

\section{Municipios y población del área afectada por los fenómenos}

El municipio de Calcahualco se ubica en la zona montañosa central del estado de Veracruz; cuenta con $134 \mathrm{~km}^{2}$ de superficie, equivalente a $0.23 \%$ de toda la entidad (Inafed, 2015a). Su superficie es generalmente muy escarpada. Este municipio constituye uno de los dos del estado de Veracruz de los que parte de su territorio conforma el área del PNPo (Secretaría de Medio Ambiente y Recursos Naturales, 2015). Su clima es templado húmedo con una temperatura promedio de $13{ }^{\circ} \mathrm{C}$ y una precipitación anual de $1148.5 \mathrm{~mm}$; su hidrografía se caracteriza por numerosos y pequeños arroyos tributarios, en su mayoría del río Jamapa, el cual recorre todo su territorio. Tiene una población total de 12929 habitantes (INEGI, 2010); 55.88 \% de sus localidades presenta un grado de marginación muy alto y en estas habitan 5440 personas (Sedesol, 2015a, p. 5). 
El municipio de Coscomatepec, al igual que el de Calcahualco, se localiza en la zona montañosa central del estado de Veracruz, al este del PNPo. Su territorio lo conforman $157.65 \mathrm{~km}^{2}$ de área escarpada, lo que representa $0.18 \%$ del estado; el clima prevaleciente en el área es templado húmedo con temperaturas promedio de $19.2{ }^{\circ} \mathrm{C}$ y una precipitación anual de $2069.2 \mathrm{~mm}$. Su hidrografía está configurada por arroyos tributarios del río Jamapa (Inafed, 2015b). El municipio cuenta con 52510 habitantes (INEGI, 2010); $46 \%$ de las localidades del municipio se encuentran con muy alto grado de marginación, concentrando a 19319 pobladores (Sedesol, 2015b, p. 5).

\section{Aspectos topográficos}

Las dos barrancas que forman parte de la zona de estudio nacen en el flanco noroeste del volcán Pico de Orizaba, arriba de los $4000 \mathrm{msnm}$ en el PNPO. La barranca del río Jamapa alberga las localidades del Rincón de Atotonilco, Atotonilco, La Mesa y Tepantitla, del municipio de Coscomatepec, así como todas las de Calcahualco (INeGi, 2015, p. 1). La segunda barranca es la del río Tliapa, a la cual tributan los escurrimientos de la Barranca Seca (INEgi, 2015, p. 1) (figura 4).

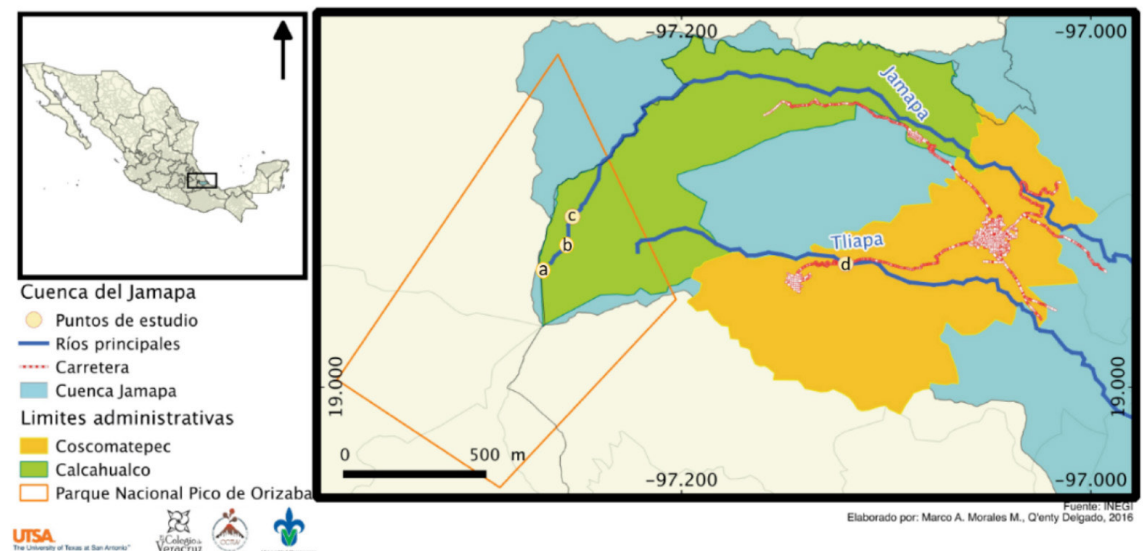

Figura 4. Flanco NE del Pico de Orizaba con indicación de los límites del PNPO, los municipios afectados y los ríos Jamapa y Tliapa. El punto "a" muestra la ubicación de la figura 5; el punto " $b$ ", la de la figura 4; el punto " $c$ ", la de la figura 2, y el punto "d", la de la figura 6. 


\section{Metodología}

Se efectuó una búsqueda documental con la finalidad de identificar fechas y sitios donde se reportaron afectaciones para los municipios de Coscomatepec y Calcahualco, lo que se logró mediante la revisión de las declaratorias de emergencia hidrometeorológicas y de documentos referentes al huracán Ernesto, ocurrido en 2012, elaboradas por las autoridades estatales, federales e internacionales (Secretaría de Gobernación, 2012; GEv, 2012; García et al., 2014; Boletín 226 de la Secretaría de Gobernación; Conagua, 2012; Brown, 2013). De igual forma, se hizo una revisión de la base de datos digital del Sistema de Inventario de Efectos de Desastres (Desinventar, 2015), la cual compiló reportes de varias fuentes (como periódicos), que evidencian los efectos del evento durante las mismas fechas (del $1^{\circ}$ al 12 de agosto de 2012) y área geográfica de estudio. Además, se recopilaron imágenes terrestres extraídas de Google Earth ${ }^{\circledR}$, que permitieran la identificación de los cambios en el paisaje después del huracán.

Más adelante, se realizó trabajo de campo para verificar in situ los cambios observados con anterioridad en imágenes de satélite. Los cambios estructurales en la barranca del Jamapa debido a flujos de agua y sedimentos se documentaron a través de fotografías en diversos sitios del PNPo por arriba de los 3000 msnm, a fin de tener un registro que pudiera servir de línea base para futuros trabajos. Los sitios se seleccionaron previamente mediante el análisis de imagen satelital procedente de la base de datos del software Google Earth Pro ${ }^{\circledR}$.

Las fotografías obtenidas en campo se compararon con fotografías previas al evento. Asimismo, se analizó el archivo histórico de Google Earth $\operatorname{Pro}^{\circledR}$, con el propósito de identificar cambios abruptos a lo largo de las cuencas de estudio.

\section{Resultados}

\section{Daños asociados al fenómeno}

Las afectaciones resultantes de las lluvias severas por el paso del huracán Ernesto el 9 de agosto de 2012 (GEv, 2012; Secretaría de Gobernación, 2012), en el caso del municipio de Coscomatepec, fueron a la infraestructura carretera y de puentes (cuadro 1), así como a las viviendas (cuadro 2). 
Afectaciones por posible asociación de eventos hidrometeorológicos y geológicos

en los municipios de Calcahualco y Coscomatepec, Veracruz

CuAdro 1. Costos por daño a infraestructura estatal en el municipio de Coscomatepec

\begin{tabular}{lcc}
\multicolumn{1}{c}{ Municipio Coscomatepec } & $\begin{array}{c}\text { Núm.de } \\
\text { acciones }\end{array}$ & Monto estimado \\
$\begin{array}{l}\text { Remoción de escombros y } \\
\text { pasos provisionales }\end{array}$ & 2 & $\$ 1025000.00$ \\
$\begin{array}{l}\text { Afectaciones en infraestructura } \\
\text { estatal (caminos y puentes) }\end{array}$ & 6 & $\$ 126633000.00$ \\
\hline Total & 8 & $\$ 127658000.00$
\end{tabular}

Fuente: Elaboración propia con datos del Cenapred en García, 2014:292

CuAdro 2. Viviendas afectadas por tipo de daño y monto estimado

en el municipio de Coscomatepec

$\begin{array}{lcccccc}\text { Municipio } & \text { Menor } & \text { Parcial } & \text { Total } & \text { Reubicación } & \begin{array}{c}\text { Enseres } \\ \text { domésticos }\end{array} & \begin{array}{c}\text { Total de } \\ \text { viviendas }\end{array} \\ \begin{array}{l}\text { Coscomatepec } \\ \text { de Bravo }\end{array} & 0 & 4 & 67 & 0 & \text { N/A } & 79 \\ \begin{array}{l}\text { Monto } \\ \text { estimado }\end{array} & \$ 0 & \$ 112 & \$ 8040 & \$ 960000 & \$ 750000 & \$ 9862000\end{array}$

Fuente: Elaboración propia con datos del Cenapred, en García, 2014:292

Los costos asociados a Ernesto en 2012 para Coscomatepec sumaron un total de 137520000 pesos. Respecto a Calcahualco, los daños se reflejaron en la infraestructura estatal como caminos y puentes (cuadro 3).

Cuadro 3. Costos por daño a infraestructura estatal

$\begin{array}{lcc}\text { Municipio Calcahualco } & \text { Número de acciones } & \text { Monto estimado } \\ \begin{array}{l}\text { Remoción de escombros y pasos } \\ \text { provisionales }\end{array} & 6 & \$ 2316000.00 \\ \begin{array}{l}\text { Afectaciones en infraestructura } \\ \text { estatal (caminos y puentes) }\end{array} & 2 & \$ 5905000.00 \\ \quad \text { Total } & 8 & \$ 8221000.00\end{array}$

Fuente: Elaboración propia con datos del Cenapred, en García, 2014:292 


\section{Revisión y análisis de imágenes Google Earth ${ }^{\circledR}$}

El análisis fotográfico por medio del archivo histórico de Google Earth ${ }^{\circledR}$ evidenció procesos de erosión por arriba de los 4000 msnm en área de la cabeza de la cuenca del Jamapa, hasta Coscomatepec, a una altura de $1500 \mathrm{msnm}$, resultando en un impacto visible a lo largo de $30 \mathrm{~km}$. El patrón de erosión en la cuenca del Tliapa es semejante al observado en la del Jamapa, iniciando a una altura similar de $4000 \mathrm{msnm}$, pero con efectos patentes sobre el cauce hasta alturas menores a $1200 \mathrm{msnm}$ cerca de la localidad de Chocaman.

Lo que parece anormal en los patrones de erosión, sobre todo en la barranca del Jamapa, es que los efectos más dramáticos dentro del canal aparentemente ocurrieron en alturas superiores a los $3000 \mathrm{msnm}$ dentro de la cuenca. Esto es algo sorprendente, porque se esperaría un incremento dramático en el caudal en las partes bajas de la cuenca al agregarse el flujo de los tributarios y, por ende, cambios más fuertes al canal en elevaciones menores.

Durante el trabajo de campo se encontraron evidencias de procesos de remoción en masa por aproximadamente $4 \mathrm{~km}$ cuenca arriba a partir del punto antes descrito por Joaquín Canchola Limón, los cuales van desde los 5 hasta los $20 \mathrm{~m}$ de profundidad (figura 5). Esto último a pesar de que en esta área, por arriba de los $3000 \mathrm{msnm}$, no se presentan afluentes perennes que tributen

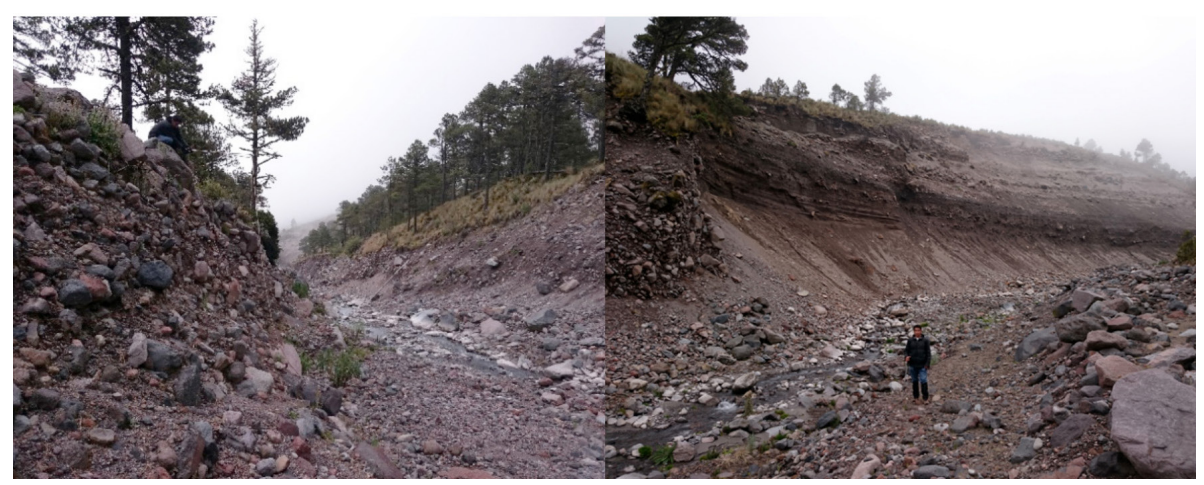

FigURA 5. Aspecto de las barrancas considerablemente profundizados durante el evento hidrometeorológico. Imagen izquierda Lat. $19.067147^{\circ} \mathrm{N}$ Lon. $-97.256864^{\circ} 0$ a 3809 msnm, imagen derecha Lat. $19.070749^{\circ} \mathrm{N}$ Lon. -97.254669 a 3753 msnm. 
constantemente a la corriente principal del Jamapa. Aun así, por arriba de los 4 $000 \mathrm{msnm}$ hay evidencia de procesos de remoción en masa a causa de agua (figura 6), y por arriba de esta altitud solo existe el intermitente flujo de agua proveniente del glaciar Jamapa en la cara norte del Pico de Orizaba.

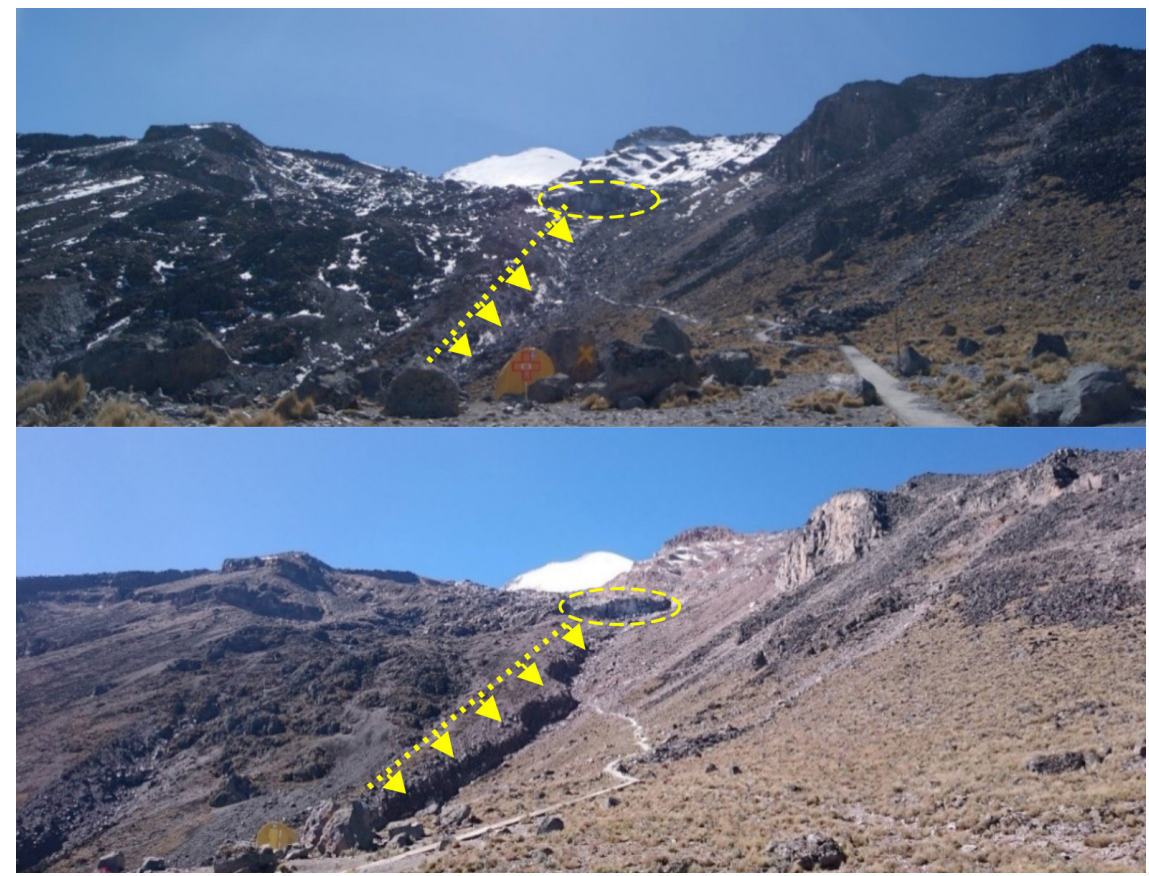

FIGURA 6. Evidencia de erosión y remoción en masa con una barranca, pasando de 8.5 a $18.5 \mathrm{~m}$ de ancho y de 2 hasta de 5 a $10 \mathrm{~m}$ en la parte baja de la imagen (marcado por la línea amarilla) y un escarpe a 4400 msnm, PNPO. La barranca se formó dentro de la rampa de la morrena glacial descrita por Palacios y Vázquez-Selem (1996, p. 15). Otra evidencia fotográfica restringe el evento de haber ocurrido entre marzo de 2012 y enero de 2013. Foto superior, diciembre de 2011, foto inferior, agosto de 2015, ambas tomadas por Morales.

Este flujo es casi enteramente subterráneo, alimentándose de agua de fusión, que emana del pie del glaciar a los $5070 \mathrm{msnm}$ y fluye hacia las cabezas de las barrancas que se localizan alrededor de los $4200 \mathrm{msnm}$, donde se ubican varios nacimientos (justo por debajo del albergue).

El paso del material y la gran cantidad de agua impactó el área de las barrancas de los ríos Jamapa y Tliapa desde arriba de los 4000 
msnm, ensanchándola y profundizándola en varios tramos (figuras 2, 3, 5 y 6). Al llegar a las partes bajas de la cuenca el río Jamapa, con fuertes escurrimientos y con los materiales erosionados ladera arriba incorporados, ocasionó importantes daños a la infraestructura de comunicaciones de Coscomatepec y Calcahualco (figura 7).

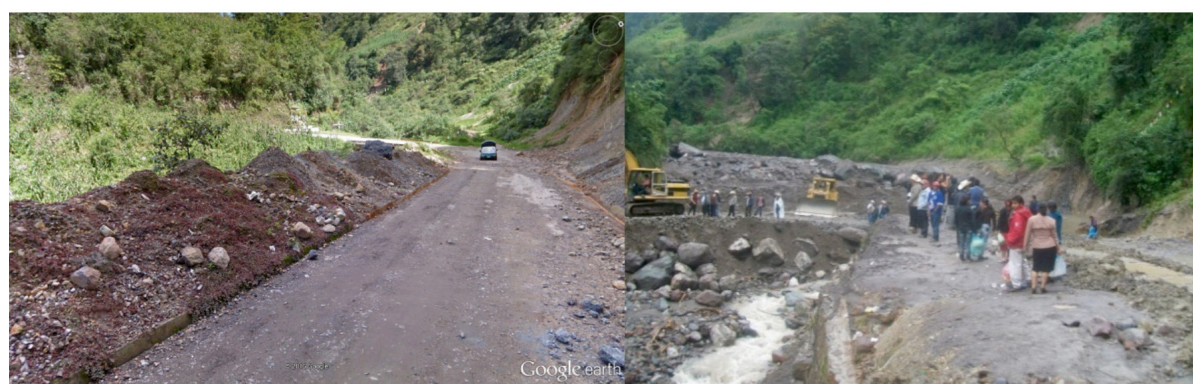

Figura 7. (Izquierda) Paso a Tetelcingo, Coscomatepec, en la barranca del río Tliapa a 1920 msnm, previo al huracán Ernesto (Google Street View, julio de 2012). (Derecha) Mismo paso después del huracán Ernesto (Facebook/tetelcingo.coscomatepecveracruz, 2012).

\section{Discusión}

A diferencia de los eventos de flujos cargados de sedimentos que se generaron durante eventos de lluvias torrenciales en el flanco sur del Pico de Orizaba en 2003 (Rodríguez et al., 2006), en este caso, la remoción de toneladas de material rocoso y sedimento volcaniclástico en alturas por encima de los 4000 msnm sucede al pie del glaciar del Pico de Orizaba y la barranca formada después del evento hidrometeorológico se encuentra en una zona sin aparentes afluentes o surcos notables, lo que sugiere un origen distinto.

Se han registrado evidencias de flujos de agua por debajo del glaciar que persiste en el volcán Pico de Orizaba, indicando la ocurrencia de procesos de deshielo predominantemente subglaciales (Weissling y Lewis, 2013).

Como se ha descrito previamente, estas aguas de fusión se infiltran con rapidez a los depósitos no consolidados (aluvión y grava) en la base del glaciar, solo para reemerger $600 \mathrm{~m}$ más abajo en la cuenca, donde varias décadas antes, campesinos locales construyeron acueductos para canalizar esta agua hacia campos de cultivos en los flancos occidentales del Pico de Orizaba. 
Estos acueductos se localizan en el área del albergue Piedra Grande y son identificables en las fotografías de la figura 6. El área superior al albergue fue descrita por Palacios y Vázquez-Selem (1996) en su estudio sobre los efectos geomorfológicos de la retracción del glaciar Jamapa, como una rampa de depósitos de morrena glacial que una vez representó el frente de la morrena terminal del glaciar Jamapa, durante el máximo glacial de la Pequeña Edad de Hielo. Además, los autores de este estudio describen la rampa como un sitio de procesos intensos de flujos de detritos posterior a un proceso de incisión de pequeñas barrancas que continúa hoy en día. Esto, unido a la observación en este trabajo del canal de erosión que apareció en la misma rampa en algún momento durante 2012, sugiere un factor geológico adicional que puede haber contribuido al evento de movimiento de masas asociado a factores hidrometeorológicos del huracán Ernesto. Lo anterior sugiere un escenario alternativo, ya que en lugar de producirse afectaciones en la cuenca baja debido al efecto de la sumatoria de pequeños volúmenes de agua de tributarios en la cuenca alta, el evento empezó en la cuenca alta del Jamapa, donde, aunado a la elevada precipitación asociada al paso del huracán Ernesto, la liberación repentina de agua subterránea provocó la desestabilización de la morrena históricamente depositada por el glaciar, causando el desplazamiento de toneladas de material en forma de un flujo de corriente normal o un flujo hiperconcentrado ladera abajo hasta incorporarse al río Jamapa.

Comparando el evento que aquí se describe con el registrado por Rodríguez, Mora-González y Murrieta-Hernández (2006), ambos presentan muestras de concentración de flujos que nacen por arriba de los $4200 \mathrm{msnm}$, no obstante, el ocurrido en 2003 no sugiere relación con deshielo glaciar ni tampoco ofrece evidencia de erosión por arriba de los $4000 \mathrm{msnm}$.

\section{Conclusiones}

La comparación de fotografías satelitales y terrestres permitió identificar rastros topográficos de erosión y remoción en masa a gran escala, que se originaron debido a flujos de agua en la cuenca alta del río Jamapa -donde se encuentra el PNPO- durante 2012, y que pudieron haber contribuido al aumento del caudal 
ya alimentado por la presencia del huracán Ernesto, ocasionando severos daños -estimados en 145741700 pesos- a la infraestructura estatal en los municipios de Calcahualco y Coscomatepec.

Debido a la erosión observada a lo largo de las barrancas del Jamapa y del Tliapa, así como al tamaño de los materiales y árboles arrastrados, queda evidenciado el impacto del evento de precipitaciones extraordinarias asociado al paso del huracán Ernesto, especialmente en conjunto con un posible evento de deshielo del glaciar en la cima del volcán.

Para explicar la falta de volumen considerable de material en la parte superior de la cuenca (arriba de los $4000 \mathrm{msnm}$, figura 6), existe la posibilidad de la remoción del material por las corrientes de agua provenientes del huracán y/o glaciar como un escenario factible, pero también de que los socavamientos se hayan producido como efecto de un hundimiento de la tierra (por el aumento del flujo de agua subterránea), ya que energéticamente es improbable remover esa cantidad de masa sobre todo por la ausencia de tributarios en el área que dirigieran los flujos. Esto quizás indica que la remoción no ocurrió en gran medida como resultado de las fuerzas de fricción debido al flujo de superficie, sino más bien dadas las presiones del agua subterránea originadas por la precipitación adicional que se dio en las laderas superiores de la cuenca.

La incidencia de estos acontecimientos debe ser estudiada principalmente por el grado de vulnerabilidad de la zona, vinculado con los bajos niveles socioeconómicos de ambos municipios, la topografía y los efectos de los eventos hidrometereológicos extremos.

Los expertos del IPCC (2007) señalan que uno de los sistemas más frágiles ante el cambio en los patrones de humedad, precipitación y temperatura es la alta montaña de latitud tropical. En este sentido, hay evidencia de que un cambio significativo en la precipitación local tiene efectos diferenciados sobre la cuenca alta y baja en el PNPO. Esta circunstancia, en consecuencia, pone en riesgo de afectación a la población.

Asimismo, los movimientos de masa asociado a los patrones de precipitación pueden contribuir de manera directa a desencadenar situaciones extremas de impacto en la infraestructura y sobre el mismo ecosistema de alta montaña, el cual es prioritario para el suministro de agua de las poblaciones de la cuenca alta y baja. De tal suerte, resulta importante mantener una red de estaciones 
meteorológicas en el área del Pico de Orizaba, especialmente en el estado de Veracruz, por la baja disponibilidad de datos hidrometeorológicos. El mantenimiento de una red de este tipo es vital para monitorear eventos hidrometeorológicos extremos y poder prevenir los desastres asociados a ellos.

Dado lo anterior, en el futuro se continuará con esta investigación en aspectos como la estimación del volumen faltante por encima de los $4000 \mathrm{msnm}$, debido a los procesos de erosión y remoción en masa, entre otros.

\section{Fuentes consultadas}

Brown, D. P. (2013). Tropical Cyclone Report: Hurricane Ernesto (AL052012). Retrieved from http://www.nhc.noaa.gov/data/tcr/AL052012_ Ernesto.pdf [2015, September $\left.2^{\text {nd }}\right]$.

Conagua. (2012). Reseña del huracán “Ernesto” del Océano Atlántico. México: Comisión Nacional del Agua. Recuperado de http://smn.cna.gob. mx/ciclones/tempo2012/atlantico/Ernesto-a2012.pdf [2015, 2 de septiembre].

Desinventar. (2015). Sistema de Inventario de Efectos de Desastres. Recuperado de http://www.desinventar.org/es/ [2015, 10 de diciembre].

García, A. N., Marín, C. R., Méndez, E. K. y Reyes, R. R. (comps.). (2014). Características e impacto socioeconómico de los principales desastres ocurridos en la República Mexicana en el año 2012. México: Centro Nacional de Prevención de Desastres-Secretaría de Gobernación.

GEV (2012). Oficio 215/2012. Solicitud de declaratoria de emergencia, por la presencia de la Tormenta Tropical "Ernesto" los días 9, 10, y 11 de agosto de 2012. Gobierno del Estado de Veracruz. Recuperado de http://www. veracruz.gob.mx/dependencias/?p $=p c$ [2015, 12 de septiembre].

Inafed. (2015a). Calcahualco, estado de Veracruz-Llave. Enciclopedia de los Municipios y Delegaciones de México. Instituto Nacional para el Federalismo y el Desarrollo Municipal. Recuperado de http://www.inafed. gob.mx/work/enciclopedia/EMM30veracruz/municipios/30029a.html [2015, 25 de noviembre].

Inafed. (2015b). Coscomatepec, estado de Veracruz-Llave. Enciclopedia de los Municipios y Delegaciones de México. Instituto Nacional para el 
Federalismo y el Desarrollo Municipal. Recuperado de http://www.inafed.gob.mx/work/enciclopedia/EMM30veracruz/municipios/30047a. html [2015, 25 de noviembre].

INEGI. (2009a). Prontuario de información geográfica municipal de los Estados Unidos Mexicanos, Calcahualco, Veracruz de Ignacio de la Llave, Clave geoestadística 30029. México: Instituto Nacional de Estadística y Geografía. Recuperado de http://www3.inegi.org.mx/sistemas/mexicocifras/datos-geograficos/30/30029.pdf [2016, 5 de marzo].

INEGI. (2009b). Prontuario de información geográfica municipal de los Estados Unidos Mexicanos, Coscomatepec, Veracruz de Ignacio de la Llave, Clave geoestadística 30047. México: Instituto Nacional de Estadística y Geografía. Recuperado de http://www3.inegi.org.mx/sistemas/mexicocifras/datos-geograficos/30/30047.pdf [2016, 5 de marzo].

InEgr. (2010). Censo de Población y Vivienda 2010. México: Instituto Nacional de Estadística y Geografía. Recuperado de http://www.censo2010.org. $\mathrm{mx} /$ [2015, 16 de mayo].

INEGI. (2015). Carta topográfica E14B46. México: Instituto Nacional de Estadística y Geografía. Recuperado de http://buscador.inegi.org.mx/se $\operatorname{arch} ? \mathrm{tx}=$ Carta + topogr \% C3\% A1fica + E14B46\&q = Carta + topogr $\%$ C3\% A1fica + E14B46\&site $=$ sitioINEGI_collection\&client $=$ INEGI_ Default\&proxystylesheet $=$ INEGI_Default\&getfields $=*$ \&entsp $=a_{-}$ inegi_politica\&lr = lang_es \% 257Clang_en\&lr = lang_es \%257Clang_ en\&filter $=1$ [2015, 28 de noviembre $]$.

IPCC. (2007). Climate Change 2007: Impacts, Adaptation and Vulnerability. Contribution of Working Group II to the Fourth Assessment Report of the Intergovernmental Panel on Climate Change. Cambridge and New York: Cambridge University Press.

IPCC. (2012). Informe especial sobre la gestión de los riesgos de fenómenos meteorológicos extremos y desastres para mejorar la adaptación al cambio climático: Resumen para responsables de políticas. En C. B. Field, V. Barros, T. F. Stocker, D. Qin, D. J. Dokken, K. L. Ebi ... y P. M. Midgley (eds.), Informe especial de los Grupos de trabajo I y II del Grupo Intergubernamental de Expertos sobre el Cambio Climático. Cambridge y Nueva York: Cambridge University Press. 
IPCc. (2013). Summary for Policymakers. In T. F. Stocker, D. Qin, G. -K. Plattner, M. Tignor, S. K. Allen, J. Boschung ... and P. M. Midgley (eds.), Climate Change 2013: The Physical Science Basis. Contribution of Working Group I to the Fifth Assessment Report of the Intergovernmental Panel on Climate Change. Cambridge and New York: Cambridge University Press.

NASA. (2016). GIOVANNI. National Aeronautics and Space Administration. Retrieved from http://giovanni.gsfc.nasa.gov/giovanni/ [2016, February $5^{\text {th }}$.

Ochoa Martínez, C. A., Welsh, R. C. M., Bonilla, J. E. y Morales, M. M. A. (2013). Fuentes de información de eventos hidrometeorológicos extremos en Veracruz de Ignacio de la Llave. Realidad, Datos y Espacio: Revista Internacional de Estadística y Geografía, 4(3), 66-73.

Palacios, D. y Vázquez-Selem, L. (1996). Geomorphic effects of the retreat of Jamapa Glacier, Pico de Orizaba Volcano (Mexico). Geografiska Annaler. Series A, Physical Geography, 78(1), 19-34.

Pierson, T. C. y Costa, J. E. (1987). A rheologic classification of subaerial-water flows. Reviews in Engineering Geology, 7, 1-12.

Rodríguez, S. R., Mora-González, I. y Murrieta-Hernández, J. L. (2006). Flujos de baja concentración asociados con lluvias de intensidad extraordinaria en el flanco sur del volcán Pico de Orizaba (Citlaltépetl), México. Boletín de la Sociedad Geológica Urbana, LVIIII(2), 223-236.

Secretaría de Gobernación. (23 de agosto de 2012). Declaratoria de Emergencia por la presencia de la tormenta tropical Ernesto (lluvia severa) el 9 de agosto de 2012, en 40 municipios del Estado de Veracruz de Ignacio de la Llave. Diario Oficial de la Federación. Recuperado de http://dof. gob.mx/nota_detalle.php?codigo $=5265156 \&$ fecha $=23 / 08 / 2012$ [2015, 2 de septiembre].

Secretaría de Medio Ambiente y Recursos Naturales. (9 de julio de 2015). Acuerdo por el que se da a conocer el Resumen del Programa de Manejo del Parque Nacional Pico de Orizaba. Diario Oficial de la Federación. Recuperado de http://dof.gob.mx/nota_to_doc.php?codnota $=5399982$ [2015, 18 de diciembre]. 
Sedesol. (2015a). Catálogo de Localidades: municipio de Calcahualco. Secretaría de Desarrollo Social. Recuperado de http://www.microrregiones. gob.mx $/$ catloc $/$ LocdeMun.aspx?tipo $=$ clave\&campo $=$ loc\&ent $=30 \& \mathrm{~m}$ un $=029[2015,10$ de agosto $]$.

Sedesol. (2015b). Catálogo de Localidades: municipio de Coscomatepec. Secretaría de Desarrollo Social. Recuperado de http://www.microrregiones.gob.mx/catloc/LocdeMun.aspx?tipo = clave\&campo $=$ loc\&e $\mathrm{nt}=30$ \&mun $=047$ [2015, 10 de agosto $]$.

Sharpe, C. F. S. (1938). Landslides and Related Phenomena. New York: Columbia University Press.

Smith, G. A. (1986). Coarse-grained non-marine volcaniclastic sediment: Terminology and depositional process. Bull. Geol. Soc. Amer., 97, 1-10.

Vargas, M. F. (1984). Parques nacionales de México y reservas equivalentes. México: Instituto de Investigaciones Económicas-Universidad Nacional Autónoma de México.

Vargas, M. F. (1997). Parques nacionales de México: Aspectos físicos, sociales, legales, administrativos, recreativos, biológicos, culturales, situación actual y propuestas en torno a los parques nacionales de México. México: Instituto Nacional de Ecología.

Varnes, D. J. (1958). Landslide types and processes. In E. B. Eckel (ed.), Landslides and Engineering (pp. 20-47). Washington, D. C.: Highway Research Board Special Report no. 29.

Varnes, D. J. (1978). Slope movement types and processes. In R. L. Schuster y R. J. Krizek (eds.), Landslide Analysis and Control (pp. 11-33). Washington, D. C.: National Academy of Sciences, Transportation Research Board Special Report 176.

Weissling, B. y Lewis, M. (13 de marzo de 2013). Recesión del hielo enigmática en un glaciar subtropical Pico de Orizaba, México. uTsa Mexico Center, Xalapa, Veracruz. 